\title{
Back-to-Back PWM Converter Fed PMSG Wind Turbine System
}

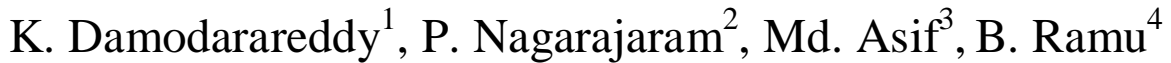 \\ (EEE, Vardhaman College of Engineering (Autonomous), JNTU, Hyderabad, India)
}

\begin{abstract}
This paper presents a DC-link voltage controller using feedback linearization technique for the PMSG wind power system for the grid voltage sag. The DC-link voltage control is achieved by the generator side converter instead of the grid-side converter. Considering the nonlinear relationship between the generator speed $(\omega \mathrm{m})$ and DC-link voltage (vdc), a DC-link voltage controller using feedback linearization technique is verified with PI and FUZZY controllers. The grid-side converter controls the grid power for MPPT. The validity of this control algorithm has been verified by simulation results for 2MW PMSG wind power system.
\end{abstract}

Keywords: - Back-to-Back PWM converter, feedback linearization, MPPT, wind power system.

\section{INTRODUCTION}

Wind power generation is the most rapidly growing energy source. Direct-drive wind energy conversion systems based on PMSG (Permanent-Magnet Synchronous Generator) have some advantages such as no gearbox, high power density, high precision, and simple control method [1], [2]. In order to achieve objectives such as continuity and security, high levels of wind power are confronted with new challenges as well as other new approaches in the power system operation. Therefore some countries have issued dedicated grid codes for connecting the wind power systems to the grid [3]. Lately, the micro- and smart-grid have been researched for the efficiency of power management [4]. However, in these systems, the grid voltage is much fluctuated in comparison with the conventional grid. Therefore, robust control of the wind power generation system is needed for grid variations. A typical configuration of a PMSG wind power system is illustrated in Fig. 1. The synchronous generator is connected to the grid through a full-scale back-to-back converter. This converter is composed of the generator side converter and the grid-side converter.

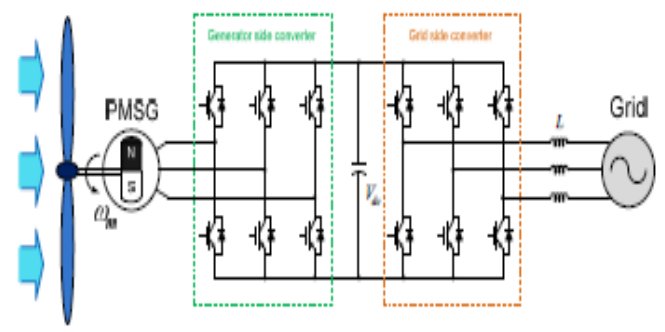

Fig.1. PMSG wind power system.

In general, DC-link voltage is controlled by the grid side converter. The grid-side converter may be out of control for the grid voltage sags in the conventional control method. When the grid fault happens, the DClink voltage is increased due to the continuous operation of wind turbine and generator. In the proposed method, the generator-side converter controls the DC-link voltage, and the grid-side converter controls the power of the PMSG wind turbine system. The DC-link voltage control strategy by the generator-side converter has been proposed in [5], [6], [7]. In the papers [5], [6], the Dc link voltage controller is not regarded as the nonlinear characteristic of wind power system. In this paper, the DC-link voltage controller using feedback linearization technique is verified with PI and FUZZY controllers. The validity of the control algorithm has been verified by simulation results for 2MW PMSG wind power system.

Wind Turbine System

\section{PMSG WIND POWER SYSTEM}

The mechanical power of wind turbine is formulated as: $P_{t}=\frac{1}{2} \rho A C_{p}(\lambda, \beta) v_{\text {wind }}{ }^{3}$

Where $P t$ : turbine power [W],

$\rho$ : air density $[\mathrm{kg} / \mathrm{m} 3]$,

$A$ : swept area [m2],

$C p$ : power conversion coefficient, 
Vwind : wind speed $[\mathrm{m} / \mathrm{s}]$.

The power conversion coefficient is a function of TSR (Tip-Speed Ratio, $\lambda$ ) and pitch angle $(\beta)$, in which TSR is defined as:

$\operatorname{TSR}(\lambda)=\frac{R \omega}{v_{\text {wind }}}$

The wind turbine is normally characterized by $P t-\omega m$ and $C p-\lambda$ curve as illustrated in Fig. 2. The turbine power is determined by the power conversion coefficient and TSR if the swept area, air density, and wind speed are constant. The power conversion coefficient and TSR depend on the aerodynamic characteristics of wind turbine. From Fig. 2, the maximum turbine power is found at point $\lambda$ op $t$ and $C$ pmax.
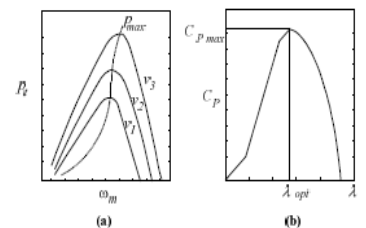

Fig. 2. Wind turbine characteristic.

(a)

Pt-wm curve, (b) $C p-\lambda$ curve

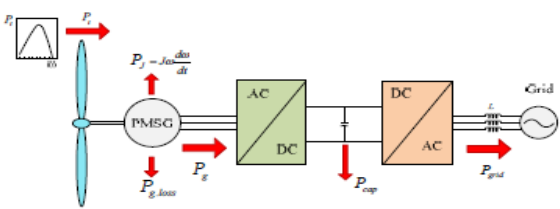

Fig. 3. Power flow of the PMSG wind power system

\section{Modeling of PMSG}

In the synchronous d-q coordinates, the voltage equation of the PMSG is expressed as follows:

$$
\begin{aligned}
& V_{d s}=R_{s} i_{d s}+L_{s} \frac{d i_{d s}}{d t}-\omega_{r} L_{q} i_{q s} \\
& V_{q s}=R_{s} i_{q s}+L_{s} \frac{d i_{q s}}{d t}+\omega_{r} L_{q} i_{d s}+\omega_{r} \lambda_{f}
\end{aligned}
$$

Where ids, iqs :

d-q axis stator currents, $R s, L s$ :

stator resistance and inductance, $L d, L q: \mathrm{d}-\mathrm{q}$ axis inductance,

$\Omega r$ : electrical angular velocity. $\Lambda f$ : magnet flux,

In the generator equipped with surface-mounted permanent magnets,

d- and q-axis inductance are same $(L d=L q)$. The electromagnetic torque $T e$ is represented as:

$$
T_{e}=\frac{3}{2} \frac{P}{2} \lambda_{f} i_{q s}
$$

\section{GENERATOR-SIDE CONVERTER CONTROL}

The operation of the grid-side converter is directly affected by grid voltage drop and then the power transferred to the grid is decreased. However, the wind turbine and generator still operate as if it is in normal condition. Therefore, in the DC-link, excessive power transferred from the generator side makes the DC-link voltage increase. To design the DC-link voltage controller, the dynamic characteristic of the whole system is considered. Neglecting the converter loss in Fig. 3, the generator power and the DC-link capacitor power can be written as:

$P_{g}=P_{t}-P_{J}-P_{g . \text { loss }}$

$P_{c a p}=C v_{d c} \frac{d v_{d c}}{d t}=P_{g}-P_{g i d}$

Where $P J$ : inertia power

Pg.loss : generator loss 
Pcap : DC-link capacitor power

Combining (6) and (7), a dynamic equation for the

PMSG wind turbine system can be expressed as:

$C v_{d c} \frac{d v_{d c}}{d t}=\frac{1}{2} \rho A C_{p}\left(\frac{R}{\lambda}\right)^{3} \omega_{m}^{3}-J \omega_{m} \frac{d \omega_{m}}{d t}$

$-P_{g .0 s s}-P_{g i d}$

In this work, the nonlinear equation in (8) will be linearized using the feedback linearization technique, which is described in the next section. The power flow of the whole system is shown in Fig. 3.

DC-link Voltage Control Adapting to Feedback Linearization

A SISO (single input and single output) nonlinear system can be expressed as follows [8]:

$$
\begin{aligned}
& {\left[\begin{array}{l}
\dot{x}_{1} \\
\dot{x}_{2}
\end{array}\right]=\left[\begin{array}{l}
f_{1}(x) \\
f_{2}(x)
\end{array}\right]+\left[\begin{array}{l}
g_{1}(x) \\
g_{1}(x)
\end{array}\right] u} \\
& y=h(x)
\end{aligned}
$$

where $x$ : state vector,

$u$ : control inputs,

$y$ : outputs,

$f, g$ : smooth vector fields,

$h \quad$ : smooth scalar function.

Comparing (6) and (7)-(10), we get

$$
\begin{aligned}
& x_{1}=v_{d c}, x_{2}=\omega_{m} \\
& f_{1}(x)=-\frac{1}{C x_{1}} \cdot P_{g i d}, f_{2}(x)=\frac{1}{J x_{2}} \cdot P_{t}-\frac{1}{J x_{2}} \cdot P_{g l o s s} \\
& g_{1}(x)=\frac{1}{C x_{1}} \cdot g_{2}(x)=-\frac{1}{J x_{2}} \\
& u=P_{g}
\end{aligned}
$$

Here, the DC-link voltage $v d c$ is selected as the output. Next, the output of the system is differentiated as $\dot{y}=A(x)+E(x) \cdot u$

$$
\text { where } A(x)=-\frac{1}{C x_{1}} \cdot P_{\text {gid }}, E(x)=\frac{1}{C x_{1}}
$$

If control input $u$ is chosen as

$$
u=E^{-1}(x)[-A(x)+v]
$$

where $v$ is the equivalent control input to be specified, the resulting dynamics become linear as

$$
\dot{y}=v
$$

Note that the idea of feedback linearization, i.e., of decoupling the nonlinearities and imposing a desired linear dynamics, can be simply applied to a class of nonlinear systems.

To eliminate tracking error in the presence of parameter variations, the new control input with integral control is given by

$$
v=\dot{y}_{r e f}-k_{1} e-k_{2} \int e d t
$$

Where $e=y-y r e f$,

yref: tracking reference

$k 1, k 2$ : controller gains. 
The gains can be determined by pole placement technique. The nonlinear DC-link voltage control block diagram is shown in Fig. 4.

From the power balance condition at the DC-link, the generator power reference is selected to be the same as the grid power. The control block diagram of the generator is shown in Fig. 5.

\section{GRID-SIDE CONVERTER CONTROL}

The maximum power of the wind turbine is calculated as maximum power coefficient and optimal tip-speed ratio.

$$
\begin{aligned}
& P_{t}=\frac{1}{2} \rho A C_{p \max }\left(\frac{R \omega_{m}}{\lambda_{o p t}}\right)^{3}=K_{o p t} \cdot \omega_{m} \\
& \text { where } K_{o p t}=\frac{1}{2} \rho A C_{p \max }\left(\frac{R}{\lambda_{o p t}}\right)^{3}
\end{aligned}
$$

From (8) and (15), the grid power reference is given by:

$P_{g i d}^{*}=K_{o p t} \cdot \omega_{m}^{3}-J \omega_{m} \frac{d \omega_{m}}{d t}-P_{g l o s s}-C v_{d c} \frac{d v_{d c}}{d t}$

The control block diagram of the grid-side converter is shown in Fig. 6.

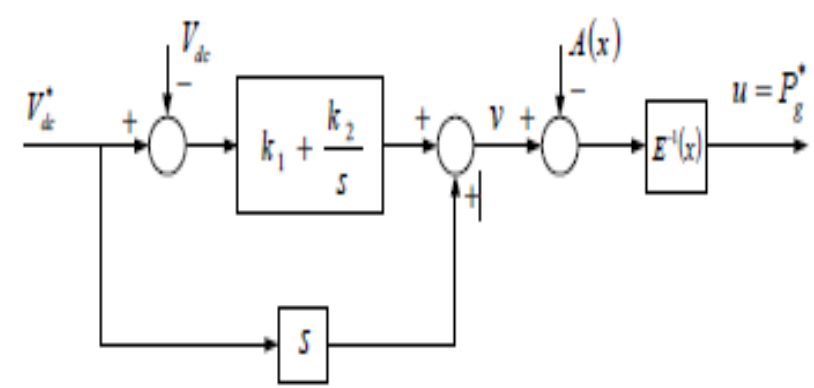

Fig. 4. Nonlinear DC-link voltage control block diagram

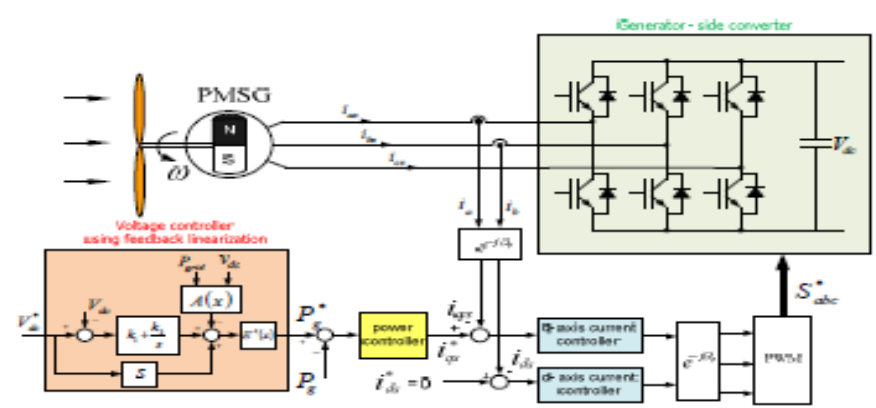

Fig. 5. Control block diagram of the generator-side converter.

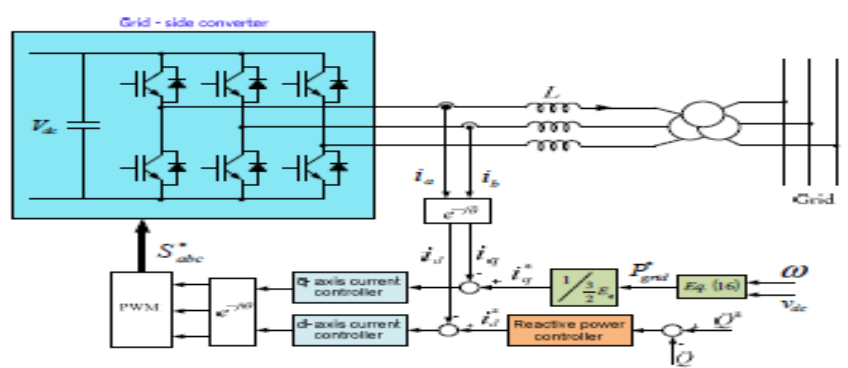

Fig. 6. Control block diagram of the grid-side converter.

V. SIMULATION RESULTS

The performance assessment of the DC-link voltage controller using feedback linearization technique with PI and FUZZY controllers for Back-to-Back PWM converter fed PMSG wind turbine system is verified using MATLAB. 
The simulation diagram and wave forms of Back-to-Back PWM converter fed PMSG wind turbine system are shown below.

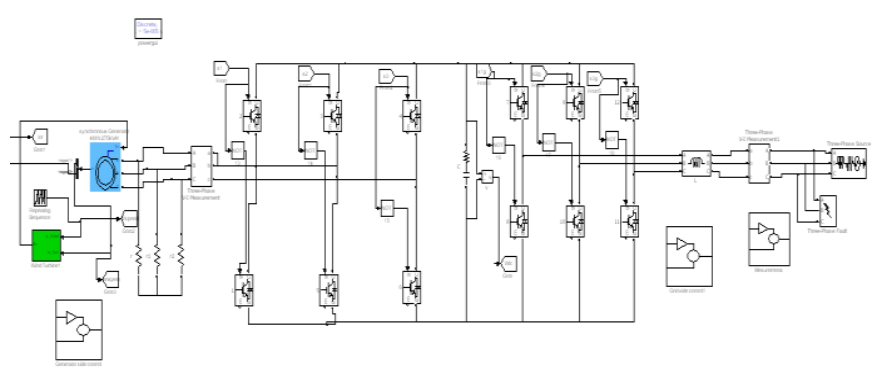

Fig.7. MATLAB Simulation Diagram of Back-to-Back PWM converter fed PMSG wind turbine system.

The simulation results have shown performances of the DC-link voltage control for 50\% drop of the grid voltage for 1 second. The DC-link voltage has been controlled within less than 6[\%]. Fuzzy controller provides good dynamic response than PI controller. The simulation diagram and waveforms of Pi controller are shown in Fig.8.

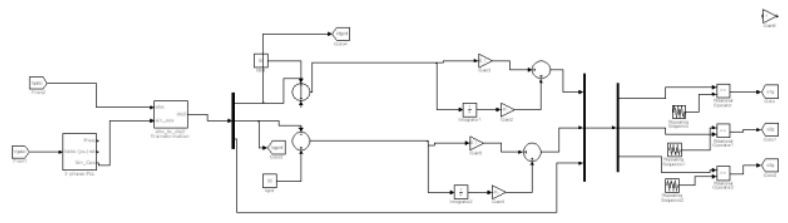

a). With grid disturbance Pi Controller

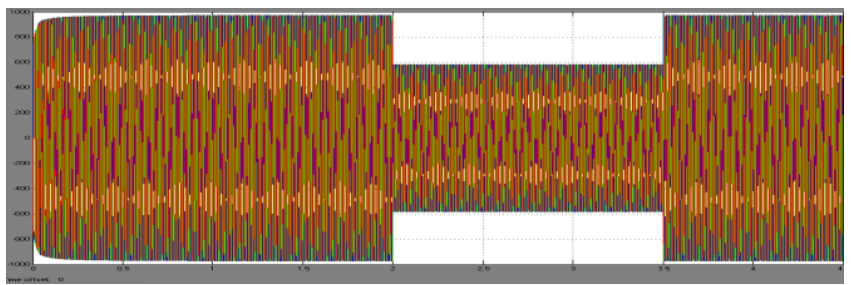

b). Wind Speed

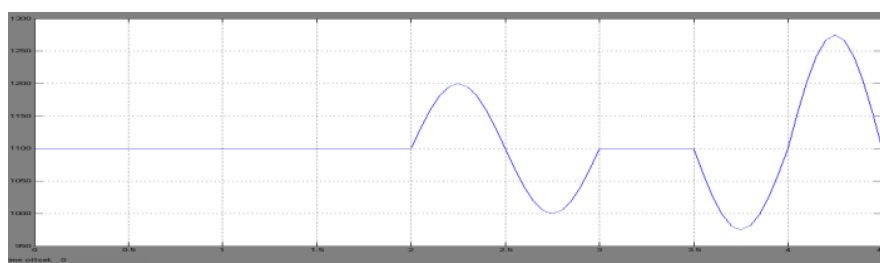

c ). DC Capacitor Voltage

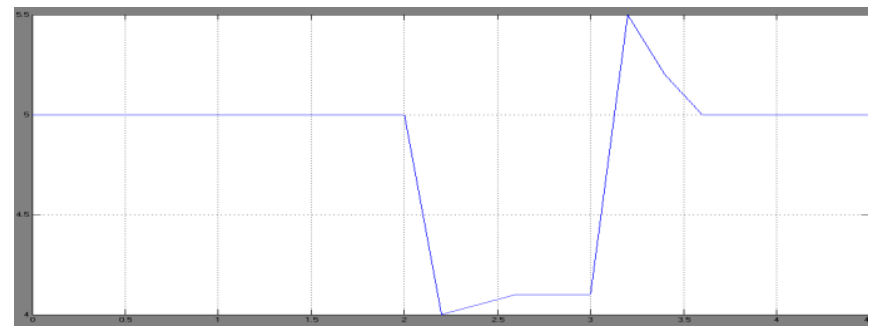

d). Generator Power 


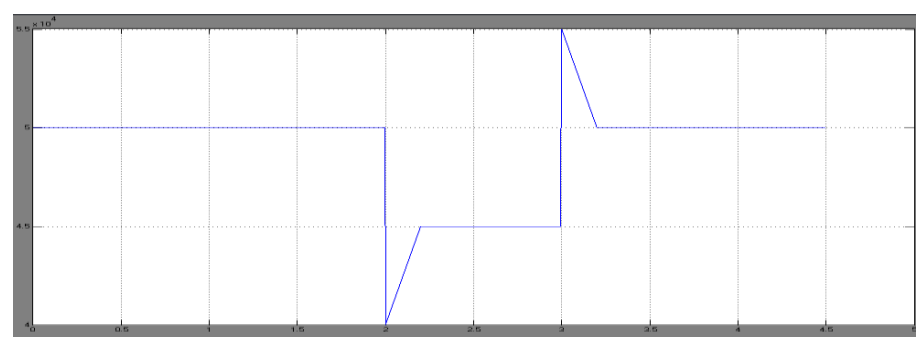

e) Grid Power

Fig.8. Simulation waveforms of Back-to-Back PWM converter fed PMSG wind turbine system with Pi Controller.

The simulation diagram and wave forms of fuzzy controllers are shown in Fig9.

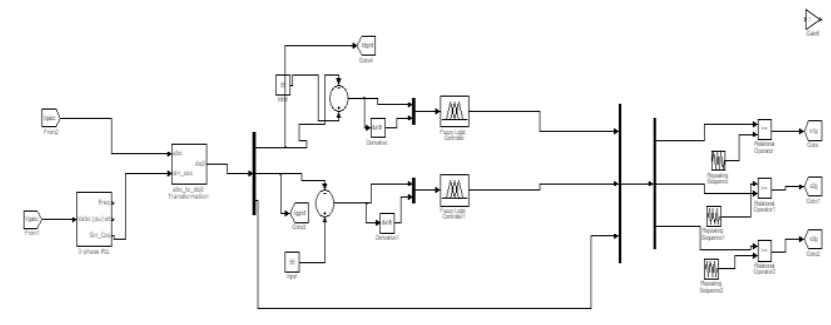

a). With grid disturbance fuzzy logic circuit

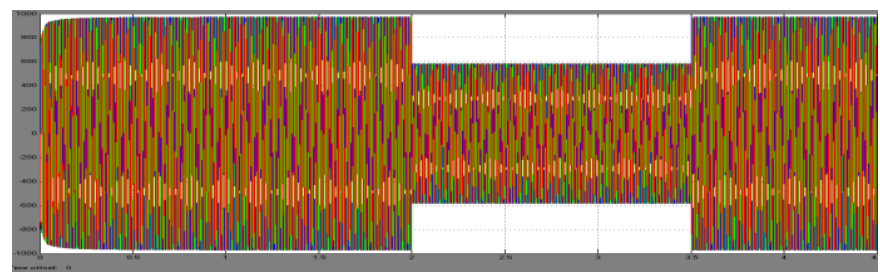

b). Wind Speed

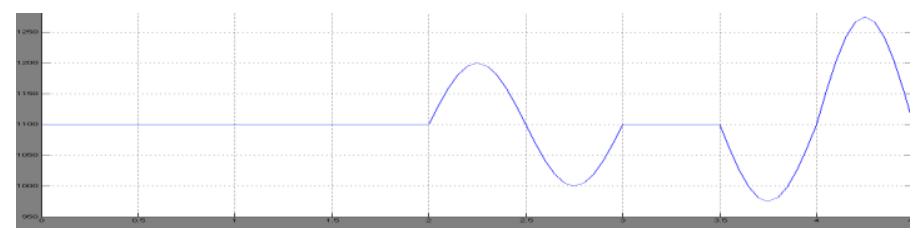

c). DC Capacitor Voltage

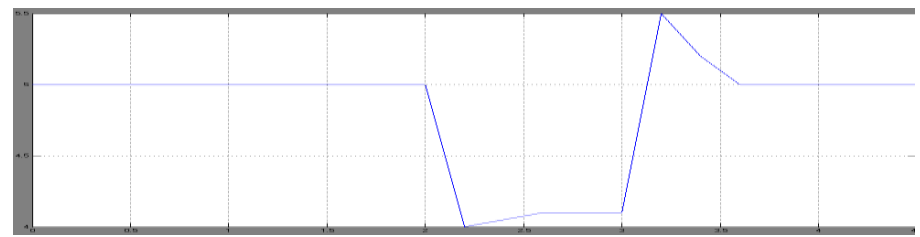

d). Generator Power.

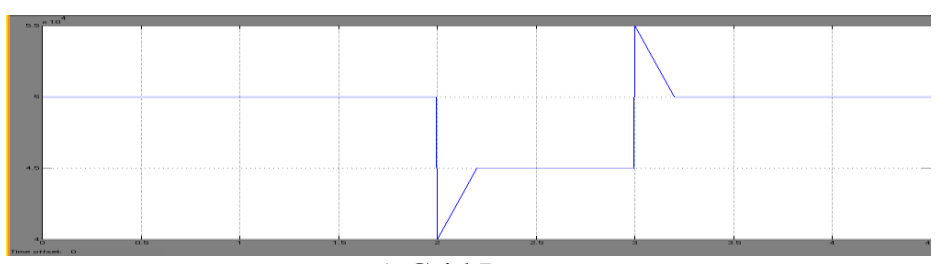

e) Grid Power

Fig.9. Simulation waveforms of Back-to-Back PWM converter fed PMSG wind turbine system with Fuzzy Logic Controller.

\section{CONCLUSION}

This paper presents the performance assessment of a DC-link voltage controller using feedback linearization technique with PI and FUZZY controllers for the variable speed wind turbine with PMSG for the grid voltage 
sags. This method is based on the DC-link voltage control by the generator-side converter. The grid-side converter controls the grid power according to MPPT strategy. The validity of the control algorithm has been verified by simulation results for $2 \mathrm{MW}$ PMSG wind power system. The simulation results have shown performances of the DC-link voltage control for 50\% drop of the grid voltage for 1 second. The DC-link voltage has been controlled within less than 6[\%]. Fuzzy controller provides good dynamic response than PI controller.

\section{REFERENCES}

[1]. Mónica Chinchilla, Santiago Arnaltes and Juan Carlos Burgos, "Control of permanent-magnet generators applied to variable-speed wind-energy systems connected to the grid," IEEE Trans. Energy Converse., vol. 21, no. 1, pp.130-135, Mar. 2006.

[2]. H. Polinder, F. F. A van der Pijl, and P. Tavner, "Comparison of direct-drive and geared generator concepts for wind turbines," IEEE Trans. Energy Convers., vol. 21, no. 3, pp. 543-550, Sep. 2006.

[3]. F. Iov, A.D. Hansen, P. Sørensen and N. A. Cutululis, "Mapping of grid faults and grid codes," Technical Report Ris $\varnothing-$ R-1617(EN), Ris $\emptyset$ National Laboratory, Technical University of Denmark, Roskilde, Denmark, Jul. 2007.

[4]. Robert Pollin, H Garrett-Peltier, and H Scharber, "Green recovery: A new program to create good jobs and start building a low-carbon economy," Center for American Progress. Sep. 2008.

[5]. Xibo Yuan, Fei Wang and Boroyevich, "DC-link voltage control of a full power converter for wind generator operating in weak-grid systems", IEEE Trans. Power Electron., vol. 24, no. 9, pp. 21782192, ep. 2009.

[6]. A. D. Hansen and G. Michalke, "Modeling and control of variable-speed multi-pole permanent magnet synchronous generator wind turbine," Wind Energy, vol. 11, no. 5, pp. 537-554, 2008.

[7]. A. D. Hansen and G. Michalke, "Multi-pole permanent magnet synchronous generator wind turbines' grid support capability in uninterrupted operation during grid faults," IET Renew. Power Genre., vol. 3, no. 3, pp. 333-348, 2009.

[8]. D. C. Lee, G. M. Lee, and K. D. Lee, "DC-bus voltage control of three-phase ac/dc PWM converters using feedback linearization,” IEEE Trans. Ind. Applicat., vol. 36, no. 826-833, pp. 826-833, May 2000 . 